\title{
XXXV. Conjectures on the cause of the peculiar condition of iron
}

\section{Dr. Schœnbein}

To cite this article: Dr. Schœnbein (1838) XXXV. Conjectures on the cause of the peculiar condition of iron, Philosophical Magazine Series 3, 13:82, 256-261, DOI: $10.1080 / 14786443808649570$

To link to this article: http://dx.doi.org/10.1080/14786443808649570

曲 Published online: 01 Jun 2009.

Submit your article to this journal $\pi$

Џ Article views: 2

Q View related articles $₫$ 
not accord with the grand total, nor can I, as I have already said, check them. I think however that there is enough to prove that on the 10th of August at least there has been nothing to support the idea of a common focus. I also must add, that on the following night there were only 3 per hour less in number."

XXXV. Conjectures on the Cause of the peculiar Condition of Iron. By Dr. Schonbein.*

SEVERAL attempts have already been made to explain

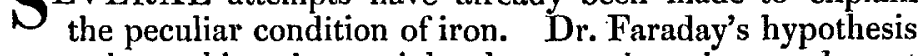
upon that subject is certainly the most ingenious and most plausible of all the theories as yet brought forward, but there are some facts pointed out by me elsewhere, which do not well agree with the views of that distinguished philosopher. As the matter alluded to is of some importance with respect to electrical science, and all the theories hitherto announced upon the cause of the anomalous relations of the iron having failed, I may, perhaps, be allowed to suggest some ideas regarding the delicate point in question. But before doing it I must not omit to say, that I do not lay much stress upon my conjectures, and that I have only ventured to make them public, because I hope they will engage some philosopher more able than myself to take up the subject, and clear up by new investigations the darkness which still invests the cause of the inactivity of iron.

Chemistry in our days accounts for the difference of qualities exhibited by what are called "isomeric bodies" by asserting that the same number of particles of the same elements are capable of grouping themselves in different ways. Now if heterogeneous atoms be capable of combining in various manners, is it not possible that homogeneous ones may do the same, and in such a way as to give rise to substances essentially distinct from each other not only with regard to their physical, but also as to their chemical properties? Sulphur, selenium, phosphorus, and carbon prove indeed that simple substances are capable of assuming states almost as different from each other as any two isomeric bodies are in qualities. It is true, the difference of properties which we sometimes observe in the same element is generally referable to a modification of the cohesive attraction of its molecules brought about by the agency of heat; but I am almost sure,

* Communicated by Mr. Faraday, to whom it had been addressed by the Author. 
that the chemical relations of a body are, more or less, modified also as often as a change of its cohesive state is effected. Sulphur for instance, in its peculiar (viscid) condition, phosphorus being liquid at the common temperature, selenium in its half fluid state, carbon as diamond, all these simple bodies are, most likely, in a chemical point of view, different from what they are in their usual condition. We certainly want as yet tests to ascertain the chemical difference which exists, for instance, between viscid and common sulphur, \&c. ; but though this be the case, analogy, I think, makes up for that want, and allows of our making an assertion of the kind. There are, indeed, many instances in chemistry which show a most intimate connexion existing between the cohesive state of a body and its chemical relations, and it would be quite superfluous to cite any such example.

Now, if by means of heat, and in some rare cases by that of light too, a number of simple substances can undergo an essential change as to their molecular aggregation, why should an agency so powerful as current-electricity, which parts asunder elements most intimately combined with one another; --I ask, why should such a force be incapable of modifying the natural cohesive state of bodies, for instance, that of iron? The conjecture, that the current which passes from that metal into a solution of blue vitriol modifies the molecular constitution of iron so as to destroy the affinity of the latter for the oxygen contained in the oxide of copper and disengaged from water by electrolytic action, is indeed a new and rather a bold one, but I should think no more so than many other conjectural views, which are now much in vogue with chemists and considered as very plausible. The fact that iron once being rendered inactive does not remain in its peculiar condition, is no proof against the correctness of my idea; for it may be said, that the modification of the molecular constitution caused by the current is, as it were, a condition forced upon the metal, a strained state, which ceases to exist as soon as its cause ceases to act. The condition may properly be compared to that in which the particles of a bent steel-spring exist.

The circumstance that inactive iron can remain untouched for any length of time within nitric acid of a certain strength without the agency of a current, is a fact which may appear to be quite irreconcilable with my hypothesis. I do not think, however, that such is the case. In the first place we must suppose that something like a "vis inertice" comes into play, that is to say, to a certain degree a tendency of the iron particles to remain in their newly assumed juxtaposition; but on the other hand we must also admit the existence of some acPhil.Mag. S. 3. Vol. 13. No. 82. Oct. 1838. 
tion on the part of the acid upon the inactive iron. It is a well-known fact that fused phosphorus does not become solid at the common temperature if surrounded by a strong solution of potash*; and according to the experiments which I have made on the sulject, phosphorus being in the circumstances mentioned can be cooled down nearly to the freezing point without becoming solid, whereas when covered with water it becomes solid at $104^{\circ}$ Fahr. Now if the presence of a solution of potash prevent phosphorus from assuming its solid state, nitric acid by an analogous action may force the particles of inactive iron to remain in their peculiar relative position.

Having ventured myself so far into the regions of conjecture, I may, perhaps, be allowed to continue my course a little longer in that direction. For aught I know, all chemical philosophers tacitly acknowledge that the chemical attractive force which a particle of any element exerts with reference to a particle of any other simple body is equal on every one of its sides, provided the distance between the two particles remains the same. Now the peculiar state of iron leads me to suspect, that the particles of that metal have each of them two chemical poles, at least with regard to oxygen, one pole which attracts the latter body, and another pole which either exerts no attraction for oxygen or which repels it. Supposing each molecule of iron to be possessed of such polar sides, it may be conceived, that a current which passes from the metal into an oxi-electrolytic fluid, into a solution of blue vitriol for instance, directs these particles so as to place their attractive poles (attractive with regard to oxygen) towards the axis of the current, or inwards with respect to the surface of the metal, and the repulsive ones towards the electrolytic fluid. Such a position of the particles would prevent them from acting either upon the oxygen disengaged at them by electrolytic action or upon the oxygen contained in the oxide of copper. It is a matter of course, according to my hypothesis, that the arrangement of the poles of the molecules of the iron would be the reverse of that just spoken of, in case the metal acted the part of the cathode of a current. I have shown that a piece of iron rendered inactive by its having been made the positive electrode within common nitric acid, is turned active again by being made the negative one. I must, however, not omit to state, that in order to make the hypothesis agree with all the facts known respecting the peculiar condition of iron, we are obliged to suppose that the polarity of the iron particles exists only with regard to oxy-

- The presence of the solution of potash, however, is not required to retain the phosphorus in the liquid state. See Phil. Mag. and Annals, N.S., vol, jii. p. 144,-EDIT. 
gen which is either in a combined state or set free by electrolytic action, and by no means to oxygen which is in its usual condition. If iron be voltaically associated with platina and put into water containing oxygen dissolved, the former metal is oxidized whether the platina be plunged into the fluid before or after the iron. If zinc be the substance put into voltaic association with iron, the latter is not in the least affected by the oxygen, which the water holds dissolved. For these last four months I have kept a combination of both metals within common water, which has been continually exposed to the air, and the surface of the iron is at this present moment as brilliant as it was when I put that metal into the water; whilst the zinc appears surrounded by a thick cloud of its oxide. In the two cases stated the electro-chemical laws hold good, whereas they do not at all agree with the phænomena which are referable to the peculiar condition of iron. I must openly confess that the different way in which the same current makes the iron act upon the oxygen appears to me as rather unfavourable to my hypothesis of a chemical polarity of the iron particles; but on the other hand it must be allowed, that the fact alluded to is likewise very much at variance with the principles of the electro-chemical system of the present day.

There is another objection to which my hypothesis will, perhaps, be thought liable. It may be said that the solid state of iron does not allow its particles the motion required for obtaining the peculiar arrangement of their poles mentioned. It is a point generally adopted by philosopbers, that the atoms of no body do immediately touch each other, and it is supposed that the distance at which any two contiguous particles are placed from each other surpasses by far the diameter of each atom. If such be the case, I cannot conceive why the molecules of iron should not be capable of being turned by some force, being superior to that by which they are kept together under ordinary circumstances. There are, indeed, some facts which put it beyond doubt that the molecular constitution of a solid body may be essentially modified without having recourse to its liquefaction or vaporization. Gustave Rose, in a very interesting paper lately published in Poggendorff's Annalen*, has demonstrated, that arragonite can easily be transformed into calcareons spar by moderately heating the former substance. Such a change cannot take place without an internal motion of the particles of carbonate of lime, the form of crystallization as well as the specific gravity of the compound becoming considerably modified under

* And of which a translation appeared in Lond, and Edinb. Phil, Mag,, vol. xii. p. 465.-EDIT. 
the circumstances. Now what heat is capable of effecting in one case, a current, I think, must be able to do in another.

As to the arrangement of the molecules of common iron with regard to the relative position of their chemical poles, it must be supposed to be similar to that of Ampère's molecular currents in the same rnetal before its being magnetized, that is to say, quite irregular. From such being the case it would follow that the surface of a piece of common iron is formed of attractive and repulsive poles, or what comes to the same thing, that the metal without being placed under the influence of a current of a certain direction, is to be chemically affected by oxygen which is in the peculiar state before mentioned.

It is not impossible that the supposed chemical polarity of the molecules of iron is in some way or other connected with the eminently magnetic properties of that metal, and it may even be imagined, that the current which is suspected of circulating round each iron particle has its source in the said polarity. As far as I know, Ampère has only postulated the currents in the iron, or rather inferred them from a certain number of facts, and given out no opinion whatever as to their ultimate cause. The passage of a current through iron must at any rate have some influence upon the relative position and motion of the supposed molecular currents of that metal, and changing the direction of these currents may also determine a modification of the chemical relations of iron. Pursuant to my hypothesis nickel and cobalt ought to be quite similar with regard to the phænomena of inactivity. Such, however, as formerly shown by me, is not the case; but on the other hand I must say, that my experiments were made upon such a small scale and were so few in number, that $I$ do not yet dare to draw any conclusive inference from them.

Isomerism and dimorphism, generally speaking so closely connected with one another, are phænomena which have, perhaps, also something to do with chemical polarity. Up to this present moment they remain unaccounted for; but if we suppose that the particle of one substance exerts towards the particle of another different degrees of attraction, according to different relative positions of these molecules, we can conceive the possibility of two bodies forming a variety of distinct compounds, though the ratio in which their constituent parts enter into combination should remain the same.

Agreeably to such hypothesis a series of isomeric bodies would be nothing but [bodies constituted by the operation of] different sorts of chemical equilibrium between the same constituent parts. It would also follow from the hypothesis, 
that amongst such a series of isomeric bodies, there is one in which the chemical equilibrium is stable, that is to say, the relative position of the chemical poles of the heterogeneous atoms such as to allow the greatest attraction between the component parts.

In closing this paper I cannot but repeat what I said at the beginning of it, namely, that $I$ do not attach much importance to the views just now developed, they being entirely hy. pothetical; nevertheless I think them not altogether unworthy of being taken into consideration. If they should happen to excite happier ideas upon the subject treated of in my paper, they will not have been quite useless.

Bâle, May 24, 1838.

XXXVI. The Specific Heats of the Gases as deduced by Dr. Apjohn, compared with the more recent Results of Dr. Suerman. By James ApJohn, M.D., M.R.I.A., Professor of Chemistry in the Royal College of Surgeons, Ireland.

To the Editors of the Philosophical Magazine and Journal. Gentlemen,

I $T$ is known to some of my scientific friends that $I$ have been for a considerable time engaged in experiments for determining the specific heats of the more remarkable gaseous bodies; and indeed several of the results at which I have arrived have been communicated to the public through the reports of the British Association and the pages of the Philosophical Magazine.* The entire of my researches on this subject have some time since been laid before the Royal Irish Academy, and have appeared in a connected form in the volume of its Transactions which has just issued from the press. As, however, the circulation of the Transactions is necessarily limited, and, also, in order that I may set myself right with the public upon some points in reference to which I have been misapprehended, I am anxious to avail myself of the pages of your Journal, to draw attention to the efforts which I have made towards the solution of a problem of acknowledged difficulty and great importance. I have also another object in making this hasty communication, viz. to bring under the notice of British philosophers the recent very able and valuable investigations of Suerman, a copy of whose memoir on the specific heats of gases has recently come into my possession.

Dr. Suerman has, as will be seen, adopted my method, and, by means of a very elaborate apparatus, has arrived at conclusions which, as I shall show, correspond very closely with

[* See L. and E. Phil. Mag., vol. vii. p. 385.] 